\title{
International Journal of Engineering and Manufacturing
}

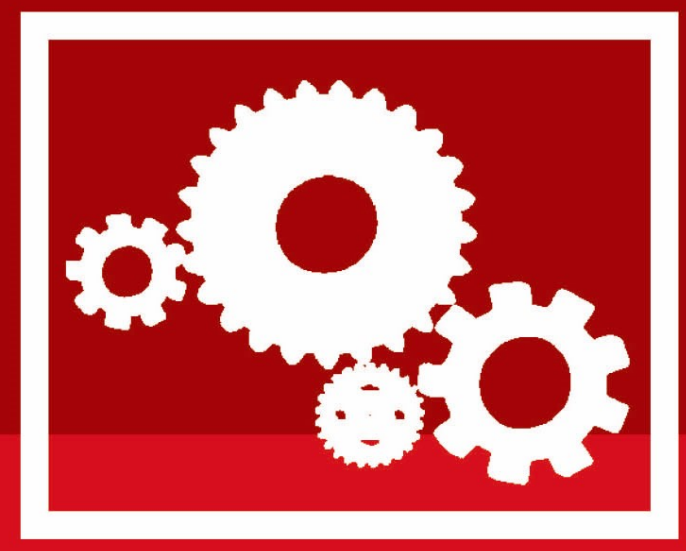




\section{International Journal of Engineering and Manufacturing (IJEM)}

ISSN Print: 2305-3631, ISSN Online: 2306-5982

Volume 10, Number 1, February 2020

\section{Contents}

\section{REGULAR PAPERS}

Optimal Capacity Determination For Electrical Distribution Transformers Based On IEC 60076-7

And Practical Load Data

Keyvan Farahzad, Aliakbar Shahbahrami, Mani Ashouri

CFD Investigation of Thermal and Pressurization Performation in LHe Tank

Wang Yuzhu, Cui Lande, Zhang Caigong, Kong Lingfen, Jia Wenlong

Multiple Master Communication in AHB IP using Arbiter

Hitanshu Saluja, Naresh Grover

Investigation of Inhibition Potential Effect of Organic Compound for the Corrosivity of Phosphoric

Acid on Aluminium

Musa Husaini, Muhammad Bashir Ibrahim

Absorption, Diffraction and Free Space Path Losses Modeling for the Terahertz Band

Oluseun.D.Oyeleke, Sadiq Thomas, Olabode Idowu-Bismark, Petrus Nzerem, Idris Muhammad 